On the other hand, an evolved Mousterian industry occurred in a silt deposit in a tributary of the Wadi Derna, associated with a vertebrate fauna and wellpreserved plant remains. This deposit interdigitates with the high terrace of the Wadi Derna, which was surveyed down-stream to a point about three-quarters of a mile from the sea. There is no doubt that this terrace was formed in connexion with a sea-level much higher than the present, though further work will be necessary before an exact estimate of the height of this level can be given.

No traces earlier than blade industries of Upper Palæolithic or later date occur on the consolidated dunes which line the modern shore, and which presumably belong to the low sea-level of the last glaciation.

Detailed information regarding the form and associated fauna of at least one phase of these later industries was obtained from a cave discovered and excavated in the Wadi Cuf, fifteen miles from the coast. The two faunas, and the flora from the Wadi Derna, should provide considerable information on the Pleistocene climatic sequence of the east Libyan seaboard.

We should like to express our gratitude for the assistance afforded by King's College, Cambridge, and the British Museum, in defraying the expenses of two of the members of the expedition, and particularly to the Trustees of the Percy Sladen Memorial Fund for their generous grant, without which the expedition would never have been undertaken. The constant help and co-operation of the authorities of the British Military Administration of Cyrenaica was also an important factor in the success of the expedition.

A further visit in the near future, to amplify and complete these findings, is planned.

\section{THE COMMON COLD}

$\mathrm{T}$ HE Cantor Lecture before the Royal Society of Arts, delivered on January 20 by Dr. C. H. Andrewes, of the National Institute for Medical Research, is an admirable summary of the essential features of our knowledge of that world-wide scourge, the common cold; and nobody is better fitted than Dr. Andrewes to state what we know and what we do not know about it. This problem is being attacked energetically by a research unit of the Medical Research Council in a hospital built at Salisbury during the War by Harvard Medical School and the American Red Cross, and eventually presented to the Ministry of Health.

If, as Dr. Andrewes showed, those who are working on this problem in Great Britain and other countries are only beginning to pick up clues to the solution of what is one of the most complex problems of virology, there is plenty of evidence that this relative ignorance will not persist for very long. All the portents, indeed, suggest that presently the common cold, like typhus, typhoid, cholera, smallpox, yellow fever and other plagues, will have yielded to human domination. But this will not come about without much patient research and, when that research has found the methods of control and cure, the co-operation of the public will be required. For, as Dr. Andrewes explained, the common cold, or more accurately, perhaps, the various varieties of it which probably exist, depend very much for their dissemination upon such human habits as sneezing, coughing, handkerchief-waving and so on-all of them habits which people will not readily alter to the degree that scientific control of infection requires.

The work of the Air-Hygiene Unit, the members of which are collaborating more and more closely with the workers on the common cold, demonstrates the importance of this aspect of the problem. It has been shown, for example, that handkerchiefs shaken in the air can disseminate very many bacteria, and other work suggests that impregnation of handkerchiefs with certain substances, among which phenyl mercuric bromide is promising, may make them less dangerous. Possibly the handling of infected handkerchiefs, rather than waving them about, may be an even more important means of dissemination of the organisms concermed.

Research on the common cold, like all work on diseases caused by viruses, was hampered untilmethods of cultivating viruses in the laboratory were discovered. Now that these are available, it is possible to use, for work on the common cold, the method of cultivation of viruses which has been more successful than any other, namely, their cultivation on the fertile hen's egg. American workers have claimed that they have successfully grown the 'cold' virus in hen's eggs; Dr. Andrewes and his colleagues, who are attacking the whole problem in Britain, have used the same techniques, but have so far been unable to confirm the American results. Dr. Andrewes discussed this point and suggested that probably the two groups of workers are studying colds due to different causes, the American type of cold being more like the condition known as sinusitis, whereas the British workers are studying the runny-nose type. Thus one of the important requirements is successful isolation and cultivation in the laboratory of the viruses concerned, of which there may be several.

Another great handicap in this work is the lack of a suitable experimental animal. The virus of human influenza will 'take' in ferrets, but the chimpanzee is the only animal so far known to be susceptible to the human common cold; and chimpanzees are expensive and difficult to handle. Human volunteers must therefore be used, and in his lecture Dr. Andr 3 wes described the work being done at Salisbury where the Medical Research Council Unit has so far had the help of five hundred human volunteers. A sound technique has now been evolved; methods of storing and filtering the virus have been worked out; it has been shown that the incubation period of the colds studied was two to three days, and that the nasal secretions will not communicate a cold if they are diluted beyond $I$ in 100 . Bacteria-free filtrates of nasal washings from volunteers with colds have produced colds in about 50 per cent of subjects, and this has happened all the year round, with possibly a lower percentage of colds acquired during the winter.

This last point will surprise those who believe that cold and wet precipitate, or even cause, colds ; but Dr. Andrewes made wise and salutary comments on this view in the section of his lecture devoted to the effect of the season and the weather, and in the interesting section on the incidence of colds in the Arctic and in Spitsbergen, where the outbreak of colds is intimately connected with the arrival and departure of ships from the outside world. This part of the lecture and also Dr. Andrewes' remarks on the value of the many cold cures that are constantly recommended should certainly be read by the "scores, perhaps hundreds" of people who have 
written to the Salisbury Unit to tell them how to solve this difficult problem.

Men of science will appreciate this lecture as an example of how to handle an intricate subject with a charm and simplicity of phrase which make it readily intelligible to everybody.

G. LAPAGE

\section{BRITISH ROCKET WEAPONS RESEARCH}

$\mathrm{T}$ HERE is nobody better qualified to discuss our war-time development of rocket weapons than Sir Alwyn Crow, and it would therefore be unprofitable to attempt to dispute the clear statement of facts which he presented as the thirty-fourth Thomas Hawksley Lecture at the Institution of Mechanical Engineers on November 21, 1947, his subject being "The Rocket as a Weapon of War in the British Forces".

Sir Alwyn first traced the development begun in 1935 of the three main types of motor which formed the basis of almost all British rocket-propelled weapons. These were steel tubes of 2 in., 3 in. and 5 in. diameter containing a solid cordite propellant charge, which was ignited at the front, the gases being discharged in each case through a single nozzle at the rear. Pointing out that from the military point of view one of the greatest advantages of the rocket propulsion of missiles is the absence of recoil forces on the projector, Sir Alwyn went on to describe how these motors were combined with different types of explosive head and projection apparatus to meet such varied demands as for anti-aircraft fire, barrage weapons for mass bombardment and airborne projectiles for land and sea targets. He also described the development of rocket motors of the high degree of reliability necessary to provide the extra thrust which enabled aircraft to take off with a much shorter run. An idea of what was achieved in these fields may be gathered from the fact that "a single craft was able to fire highly lethal ammunition on the chosen target area at the rate of half a ton a minute for nearly a minute at a time", and the hitting power of a single aircraft was "momentarily the equivalent of the full firing power of a medium cruiser".

As this was his main concern, Sir Alwyn's paper dealt primarily with the detailed development of solid-fuelled rockets to meet a number of specific requirements; but since there can be little doubt that British progress in the field of rocket development at the end of the War was some ten years behind that of the Germans, it would be interesting if Sir Alwyn could be persuaded to present his views on a number of the other aspects of this type of armament, aspects which must have been the subject of much discussion because of their fundamental nature. Were difficulties of production and the impossibility of making the necessary research in the early stages the obstacles that precluded the use of liquid fuels, with the enhanced index of performance which would be expected from them ? Why was so much greater emphasis placed on fin stabilization than on spin stabilization? Was progress made in the examination of methods of control and guidance of the projectile during its flight, or was it considered in Britain that the inherent advantages of the unguided weapon outweighed any which might accrue from guidance ? Even our choice of solid propellants appears to have been very limited, and it would be interesting to know what attempts were made to develop other types. The use of light alloy tubing for the motor body would seem to be an obvious way to increase the charge/weight ratio, and the steps made to investigate its possibilities would be worth knowing.

The only fair criticism which can perbaps be made of Sir Alwyn's lecture is that he made no mention of the aiming and sighting equipment developed to ensure that the projectiles would arrive at the right spot at the right moment, for if they fail to do this all the ingenuity lavished on the design of the weapon is useless.

R. H. MACMILLAN

\section{PHOTO-ELASTICITY IN MECHANICAL ENGINEERING}

$T$ WO papers which make a very useful addition to the sparse literature on photo-elasticity were presented to the Institution of Mechanical Engineers on December 12, 1947. Mr. W. A. P. Fisher's paper dealt with the basic physical properties of model materials which are relied upon in the 'frozen stress' technique of three-dimensional stress analysis. This technique, which was originated in Germany and the United States, is based on the fact that certain photo-elastic model materials have a very low Young's modulus at elevated temperatures and consequently suffer considerable deformations under small loads. If such small loads remain in position during subsequent cooling, it is found that the materials set in the strained position and retain, after the removal of the loads, virtually the whole of the strain and the photo-elastic effect associated with the loading at the elevated temperature; hence the term 'frozen stress'. This phenomenon is utilized in three-dimensional analysis by cutting thin slices from a threedimensional model, which can then be examined in a photo-elastic polariscope in accordance with the ordinary two-dimensional technique. The 'frozen stress' patterms are not found to be appreciably disturbed by careful cutting.

The major part of Mr. Fisher's paper was devoted to a discussion of the suitability of phenol-formaldehyde resins, particularly 'Catalin 800 ', for use with this technique. In the United States, glyptal resins have been used for this purpose almost without exception but as this material is very expensive and difficult to obtain in Britain, considerable interest is attached to the detailed investigation of the merits of 'Catalin' which was carried out at the Royal Aircraft Establishment, Farnborough, by Mr. Fisher. Data were given in the paper of the physical properties of 'Catalin', both at room temperature and at its softening temperature. Young's modulus at $80^{\circ} \mathrm{C}$. appears to be about $1 / 120$ of the value at room temperature. The paper also contained some practical illustrations of the 'freezing' technique.

Mr. R. B. Heywood's paper on "Some Modern Applications of Photo-elasticity" contained a brief outline of photo-elastic theory and a summary of the properties of the more important model materials, followed by some interesting examples of applications to design problems taken from the field of mechanical engineering.

It will be an encouragement to everyone interested in photo-elasticity that the engineering institutions are once more, after a long interval, taking an interest in this valuable method of stress analysis.

E. K. FrankL 